\title{
The Instability Of Tax Revenue And The Missing Risk Premium
}

Syed M. Ahsan, Concordia University, Canada and CESifo

Panagiotis Tsigaris, Thompson Rivers University, Canada

\begin{abstract}
This paper attempts to estimate the implicit risk premium from fluctuating tax revenue. We provide a number of reasons for the absence of the risk premium from the public borrowing rate. One reason can be viewed as the value society places on the ability of the tax system to act as an automatic built-in stabilizer. Empirically the annual value of this implicit risk premium for the US is the estimated at 2.45 percent.
\end{abstract}

Keywords: Discount Rates; Implicit Risk Premium; Aggregate Risks; Instability of Tax Revenues

\section{INTRODUCTION}

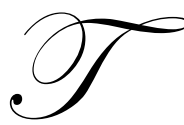

ax revenue accruing to the government, being primarily functions of the aggregate return to labour and capital, embodies systematic risk. Thus when public debt is issued to fund a new expenditure, government is forced to resort to using future 'risky' revenues to service the debt and eventually to pay it off. Thus if investors were to appraise long-term government bonds like any other private contingent claims, they would be led to value the risk implicit in the future tax revenue flows. While the macro aggregates such as labour or even capital income at the national level may allow a greater degree of idiosyncratic risk-pooling than say the collateral put up by private borrowers, it is not plausible that future tax revenues would be riskless in the aggregate.

The instability of tax revenue is heightened due to the built-in automatic stabilization policy and, where relevant, the deliberate counter-cyclical fiscal measures. The state through progressive taxation and built-in transfers helps smooth net receipts of households and firms. The policy cushions an agent's hardship during bad economic times; by the same token, during economic prosperity it allows the government to collect more in taxes and give less in transfers. In severe downturns governments also devise discretionary fiscal interventions which add additional instability to the revenue-expenditure system. While the latter are not in the nature of 'built-in' measures, these have nevertheless been routinely employed by most governments in the post-War period. These tools of economic stabilization reduce the systematic risk the private sector faces at a given point in time and transfer it to the government budget.

The objective of this paper is to determine the implicit risk premium that risk-averse investors would ideally demand in order to hold government bonds in the full knowledge that the yields are backed by risky tax revenues, but ignore the fact that coercive powers of the state may make the interest obligations fully secure. A methodology is developed in order to identify the implicit risk premium in various tax revenue flows. Possible applications of the methodology described in the paper can be used to estimate risk premiums of different types of human capital investments, small business valuations, social insurance benefits, and other publicly non-traded assets. A number of reasons as to why the government can borrow at a lower rate than the risk adjusted discount rate are also discussed this paper.

The balance of the paper proceeds as follows. In section 2 the basic methodology of evaluating the risk premium for non-traded assets is presented. Section 3 applies the above methodology to the case of tax revenue flows. Section 4 provides an estimate for the implicit risk premium in these flows. Section 5 offers alternative explanations as to why the above risk premium is absent from government bonds and offers concluding remarks. 


\section{METHODOLOGY FOR VALUING THE IMPLICIT RISK PREMIUM}

In order to model the risk premium implicit in tax revenue flows, one needs to conceptualise the current market price of future revenue entitlement. To motivate the discussion, consider a government currently willing to borrow the market value of its future revenue claims (due $k$-periods from now). As ${ }^{\text {sum }}{ }^{\text {ing }}{ }^{\text {that }}$ investors hold a diversified portfolio, they would calculate the risk embedded in the asset by ${ }^{\text {evaluat } i n g ~}{ }^{\text {the }}$ systematic risk of the future tax revenue stream, $\mathrm{j}$. Once a particular tax revenue flow has been assigned a "price", one is led to the idea of the return that the holder of the entitlement would earn from such a hypothetical debt instrument. $\mathrm{R}^{\text {ational }}$ portfolio ${ }^{\text {investors }}$ would therefore be willing to lend to the issuer at time ${ }_{-}$an expected amount ${ }_{j t}{ }_{t}$ in exchange of the promise of the expected value of the stochastic flow ${ }_{j, t+k_{-}}{ }_{-}$periods later such that:

$P_{j, t}=E_{t} \sum_{k=0}^{\infty} \frac{R_{j, t+k}}{\left(1+\delta_{j}\right)^{k+1}}$.

In the expression above, $P_{j t}$ may be interpreted as the current "market price" of a claim on the future expected revenue stream' $\left(R_{j, t+k}\right)$, while $E_{t}$ denotes the expectations operator, and $\delta_{j}$ is the risk discount rate. ${ }^{1}$ The discount rate that explicitly adjusts for the riskiness of the revenue stream may be given by the security market equilibrium condition which states that the expected return on an investment equals the sum of the risk free rate and a risk premium term that is proportional to the excess return on the market portfolio given by:

$$
E\left(\delta_{j}\right)=r_{f}+\beta_{j}\left(E\left(r_{m}\right)-r_{f}\right)
$$

where $E\left(\delta_{j}\right)$ is the expected discount rate, $r_{f t}$ is the risk free rate, $E\left(r_{m}\right)$ is the expected market return and $b_{j}=\frac{\operatorname{cov}\left(r_{j, t}, r_{m, t}\right)}{\operatorname{var}\left(r_{m, t}\right)}$ measures the systematic risk of the security. ${ }^{2}$

The security market line can be used to empirically obtain the risk premium associated with securities that actually trade in the market since asset prices and dividend yields are observed. In the case of non-traded assets, the security market line is not applicable since the beta coefficient cannot be computed due to the non-existence of data on asset prices. Below is a description of an alternative methodology for measuring the implicit risk premium on nontraded assets.

The starting line towards the development of the implicit risk premium is to compare the determinants of the returns of two assets. One asset, say asset-i, is actively traded in the market while the other asset, say asset-j, is not.

Next, we make the reasonable assumption that the price to earnings ratio (PER) of a traded asset is mean reverting and hence stationary around a long run equilibrium value. Denoting the price behaviour of a traded asset- $i$ at time-t, $P_{i t}$, and the earnings per share, $I_{i t}$, the price to earnings ratio is hypothesized to follow a simple autoregressive process:

$$
p_{i t}=c_{0}+c_{1} p_{i t-1}+u_{i t} \text {, }
$$

\footnotetext{
${ }^{1}$ In the finance literature this basic valuation formula has been disputed on grounds that asset prices display excessive volatility relative to the anticipated stream of future dividends (Shiller, 1981).

${ }^{2}$ For the development of the capital asset pricing model and the security market line, see Sharpe (1964), Lintner (1965) and Mossin (1966).
} 
where $p_{i k}=\ln \left(\frac{P}{I}\right)_{i t}$, and $0<c_{1}<1$ with $u_{i t}$ a random error term. The long run steady state (or, unconditional mean) of the logarithm of the price to earnings ratio is: $E\left\{p_{i t}\right\}=\frac{c_{0}}{1-c_{1}}$. The assumption of stationarity guarantees that the price to earnings ratio is mean reverting. Figure 1 shows the historical price to earnings ratio for the Standard and Poor 500 index. ${ }^{3}$ For the S\&P 500 index (1872-2008), the estimation of the above equation is shown below as:

$$
\begin{aligned}
& \ln (\hat{P} / I)_{t}=0.6898+0.7418 \ln (P / I)_{t-1} \\
& t-\text { stats } \quad 4.396 \quad 12.66 \\
& \mathrm{~s}=0.242, \text { Adj. } \mathrm{R}-\mathrm{Sq}=0.541
\end{aligned}
$$

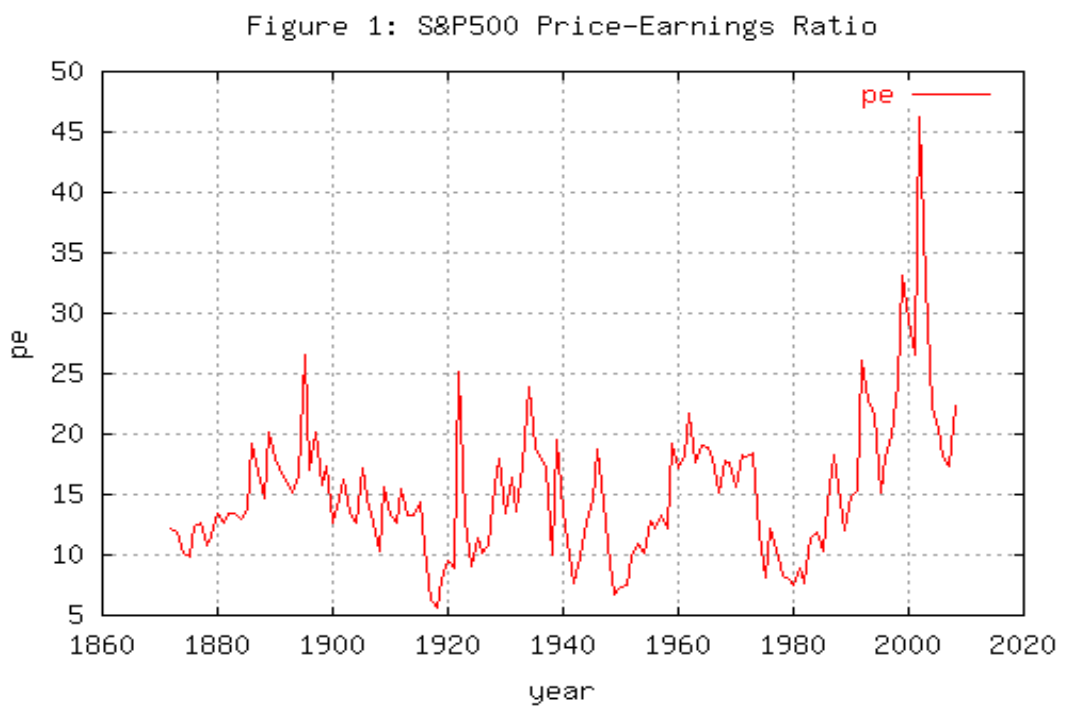

In order to examine whether the price to earnings ratio is stationary, the Dickey-Fuller (1979) test was applied by estimating: ${ }^{4} \Delta p_{i t}=a_{0 i}+\gamma_{1 i} p_{i t-1}+\xi_{i t}$. The estimated coefficient of $\gamma_{1 i}$ is -0.258 , and has a $t$-value of 4.41. Therefore, one can reject the null hypothesis of non-stationarity at the $1 \%$ level of significance. The price to earnings ratio of the S\&P 500 index (1871-2008) is therefore mean reverting. The PER is reverting to its historical average value, estimated to be approximately 14 . Given this hypothesis, the steady state the growth rate of the price of a traded asset-i will equal the growth rate of its earnings per share: ${ }^{5}$

$$
E\left(g\left(P_{i t}\right)\right)=E\left(g\left(I_{i t}\right)\right)
$$

where $g(x)$ denotes the growth rate of any variable- $x$, a notational feature that this paper shall maintain throughout.

\footnotetext{
${ }^{3}$ The data used here are taken from Robert Shiller's homepage: http://www.econ.yale.edu/ shiller/.

${ }^{4}$ The critical value from the Dickey Fuller table is -3.42 . No lagged terms were necessary since the residuals from this regression behaved appropriately.

${ }^{5}$ Using Shiller's historical annual series from 1871-2008 confirms the equality of the unconditional means of the two series. The annual average geometric growth of the S\&P500 index adjusted for inflation during this period of time was $2.17 \%$ with a standard deviation of $17.3 \%$, while the earnings per share grew at $0.997 \%$ with a standard deviation of $24.7 \%$. Thus the difference in sample means is $-1.177 \%$ with the t-statistics from a paired difference test equal to 1.21 . Thus one cannot reject the hypothesis that the unconditional means are equal in the long run.
} 
Suppose a second asset-j is introduced, which is not traded in financial markets but has a claim on a particular risky tax revenue flow. We introduce the notion of the imputed price to earnings ratio (IPER) as a measure to evaluate risk. The minimal condition that will be required here is that the IPER be defined, and that it be stationary. While it is required that the IPER for asset-j is governed by a stationary process, its unconditional mean may well be different from that of asset-i. However, asset-j will also satisfy the long run condition that $E\left\{g\left(P_{j t}\right)\right\}=E\left\{g\left(I_{j t}\right)\right\}$ much as if it were actually traded in the market.

The expected return from any security is not just the price appreciation component but also includes dividend yields. The expected total return from an investment- $z$ is therefore given by the sum: $E\left(r_{z t}\right)=E\left(g\left(P_{z t}\right)+d_{z t}\right), z=i, j$, etc. Thus in the long run, the following is true about the difference in expected returns of the two assets:

$$
E\left(r_{i t}\right)-E\left(r_{j t}\right)=E\left(g\left(I_{i t}\right)+d_{i t}\right)-E\left(g\left(I_{j t}\right)+d_{j t}\right)
$$

Differences in the expected returns are governed by differences in the expected growth of earnings and dividend yield of the respective assets. Until now we have used only unconditional means. In order to derive the implicit risk premium a model is required which determines the above variables. Thus the estimation of the implicit risk premium becomes conditional on the model used and on the information set available to the investor.

First, assume that the rate of return on the assets is governed by the security market line as indicated in equation 2.2. The growth of earnings plus dividends depends on a set of macroeconomic and firm specific variables contained in the vector set $\Omega$. Substituting these conditions into equation (2.5) yields: ${ }^{6}$

$$
\left(b_{i}-b_{j}\right) E\left(r_{m t}-r_{f t} \mid \Omega_{m}\right)=E\left(g\left(I_{i t}\right)+d_{i t} \mid \Omega_{i}\right)-E\left(g\left(I_{j t}\right)+d_{j t} \mid \Omega_{j}\right)
$$

In order to determine the beta of an asset that is not traded actively, hypothesize that the conditional expected growth rate of earnings plus the dividend yield for any asset-k depends, amongst other variables, on the growth rate of GDP, $g(Y)$, (or, for that matter, any common aggregate indicator embodying systematic risk, i.e., $\left.g(Y) \in \Omega_{\mathrm{k}}, \mathrm{k}=\mathrm{m}, \mathrm{i}, \mathrm{j}\right)$ ). Furthermore, the conditional expected excess return of the market also depends on this same macro variable. Taking the partial derivatives on both sides of 2.6 with respect to the growth rate of the economy, $g\left(\mathrm{Y}_{\mathrm{t}}\right)$ :

$$
\left(b_{i}-b_{j}\right) \frac{\partial E\left(r_{m t}-r_{f t} \mid \Omega_{m}\right)}{\partial g\left(Y_{t}\right)}=\frac{\partial E\left(g\left(I_{i t}\right)+d_{i t} \mid \Omega_{i}\right)}{\partial g\left(Y_{t}\right)}-\frac{\partial E\left(g\left(I_{j t}\right)+d_{j t} \mid \Omega_{j}\right)}{\partial g\left(Y_{t}\right)}
$$

Assume that one of the assets represents the market portfolio, say asset- $i$, (i.e., let $i=m$ ), then (2.7) simplifies since the market's beta is known to be unity as follows:

$$
b_{j}=\frac{\frac{\partial E\left(r_{m t}-r_{f t} \mid \Omega_{m}\right)}{\partial g\left(Y_{t}\right)}-\frac{\partial E\left(g\left(I_{m t}\right)+d_{m t} \mid \Omega_{m}\right)}{\partial g\left(Y_{t}\right)}}{\frac{\partial E\left(r_{m t}-r_{f t} \mid \Omega_{m}\right)}{\partial g\left(Y_{t}\right)}}+\frac{\frac{\partial E\left(g\left(I_{j t}\right)+d_{j t} \mid \Omega_{j}\right)}{\partial g\left(Y_{t}\right)}}{\frac{\partial E\left(r_{m t}-r_{f t} \mid \Omega_{m}\right)}{\partial g\left(Y_{t}\right)}}
$$

The first term in 2.8 is zero $\frac{\partial E\left(r_{m t}-r_{f t} \mid \Omega_{m}\right)}{\partial g\left(Y_{t}\right)}=\frac{\partial E\left(g\left(I_{m t}\right)+d_{m t} \mid \Omega_{m}\right)}{\partial g\left(Y_{t}\right)}$ provided that the risk free rate is

\footnotetext{
${ }^{6}$ In effect it is assumed that the non-traded asset would be priced according to the security market line.
} 
not affected by changes in the growth rate of output This equality condition can be derived from condition 2.4 which is the outcome of a stationary price to earnings ratio. Alternatively this assumption can be tested using arbitrage pricing theory (APT). The excess market return according to APT as developed by Ross (1976), and later expanded by Chen, Roll and Ross (1986) and Burmeister and Wall (1986) is, amongst others, determined by macroeconomic factors such as unexpected GDP fluctuations. According to the APT model, the market risk premium is related to GDP via a beta sensitivity parameter, $\lambda_{m}$ which measures the sensitivity of the market risk premium to unexpected movements in the growth rate of GDP. ${ }^{7}$ Hence in expectation terms, the market risk premium changes with the growth rate of output as follows: $\frac{\partial E\left(r_{m t}-r_{f t} \mid \Omega_{m}\right)}{\partial g\left(Y_{t}\right)}=\lambda_{m}$. Thus for the first term in 2.8 to be zero it must be the case that $\lambda_{m}=a_{m}$ where it is assumed that the market's earnings growth plus dividend yield are sensitive to economic growth as well: $\frac{\partial E\left(g\left(I_{m t}\right)+d_{m t} \mid \Omega_{m}\right)}{\partial g\left(Y_{t}\right)}=a_{m}$. The estimation of the two models over the sample period 1950-2008 is illustrated in table 2.1 using seemingly unrelated regression equations since the error terms might be correlated: ${ }^{8}$

$$
\begin{aligned}
& \left(r_{m t}-r_{f t}\right)=\lambda_{0}+\lambda_{m}\left(g\left(Y_{t}\right)-\bar{g}\right)+e_{m t} \\
& \left(g\left(I_{m t}\right)+d_{m t}\right)=a_{0}+a_{m}\left(g\left(Y_{t}\right)-\bar{g}\right)+u_{m t}
\end{aligned}
$$

Table 2.1: Sensitivity of Market to Economic Fluctuations

\begin{tabular}{|l|c|c|c|c|}
\hline & $\begin{array}{c}\text { Constant } \\
\text { Term }\end{array}$ & Sensitivity Factor & $\begin{array}{c}\text { Adjusted } \\
\text { R-Square }\end{array}$ & System R-Square \\
\hline Excess Returns of the & $\begin{array}{c}0.0573 * \\
(0.016)\end{array}$ & $\begin{array}{c}3.266^{*} \\
(0.748)\end{array}$ & 0.244 & 0.276 \\
S\&P500 & 0.0434 & $2.915 * *$ \\
Growth rate of & $(0.028)$ & 0.081 & \\
earnings + dividend & $(1.275)$ & & \\
yield of the S\&P500 & (0) & & \\
\hline
\end{tabular}

Note: Standard errors are reported in parenthesis. * indicates significant at the $1 \%$ level. ** at the $5 \%$ level. Cross equation restriction holds as the Wald chi-square statistics yields a p-value of 0.80

The cross equation restriction $\lambda_{m}=a_{m}$ is not rejected. The intercept term in the first equation of table 2.1 indicates the sample average excess return over the 1950-2008 sample periods, i.e., the market risk premium is estimated at 5.73 percent. ${ }^{9}$ Over the same sample period (1950-2008), the geometric mean real return on the S\&P500 index has been 7.9 percent annually (inclusive of dividends). Similarly, the intercept term of the second equation in table 2.1 indicates the growth rate of earnings plus dividends to be 4.34 percent.

Therefore, given the restriction, along a steady state the following expression emerges for asset-j's beta:

$$
b_{j}=\frac{\frac{\partial E\left(g\left(I_{j t}\right)+d_{j t} \mid \Omega_{j}\right)}{\partial g\left(Y_{t}\right)}}{\frac{\partial E\left(r_{m t}-r_{f t} \mid \Omega_{m}\right)}{\partial g\left(Y_{t}\right)}}=\frac{a_{j}}{\lambda_{m}}
$$

\footnotetext{
7 This analysis is not affected by introducing multiple factors since these additional factors are unexpected changes in macroeconomic variables and unrelated to unexpected changes to GDP growth.

${ }^{8}$ The sensitivity is estimated by expressing the output term as a deviation from the trend level, and suitably adding a constant term. This yields the single factor arbitrage pricing model.

${ }^{9}$ These figures are in accordance with the equity premium literature [e.g., Mehra and Prescott (1985)].
} 
Thus if the two sensitivities are equal $\left(a_{j}=\lambda_{m}\right)$ then the beta of the "non-traded" asset is unity $\left(b_{j}=1\right)$ just like the market's beta. Otherwise, if $a_{j}$ is smaller (larger) than $\lambda_{m}$, the beta will then be smaller (greater) than unity. For example, if the non-traded asset's growth rate of earnings and dividend yield is not sensitive to fluctuations in the growth rate of economy, then the beta will be zero implying no market risk premium due to economic fluctuations. Thus the beta of any asset is determined by the ratio of the relative sensitivities of the asset's sensitivity factor with respect to the state of the economy relative to the market's risk premium sensitivity with respect to the economy. The above analysis therefore illustrates a procedure by which one may empirically estimate the beta coefficient, and thus the risk premium, for a non-traded asset. ${ }^{10}$ From equation 2.9 , to estimate the beta, one only needs to estimate one additional parameter, namely $a_{j}$, and there is no need to have information on the asset's price.

\section{SENSITIVITY FACTOR OF REVENUE FLOWS}

In this section, an attempt is made to estimate the sensitivity of tax revenue to that of economic growth in order to obtain a reliable estimate of the sensitivity factor in the numerator of equation 2.9. The implicit risk premium is estimated on the following tax revenue flows; personal income tax (PIT), corporate income tax (CIT), social insurance contributions (SIC), excise tax (EXT), and total tax revenue streams (TOT). The interpretation of the various revenue categories- $j$ are examples of the implicit yields on the corresponding asset- $j$, which serve as the second asset as analytically modelled in section 2 .

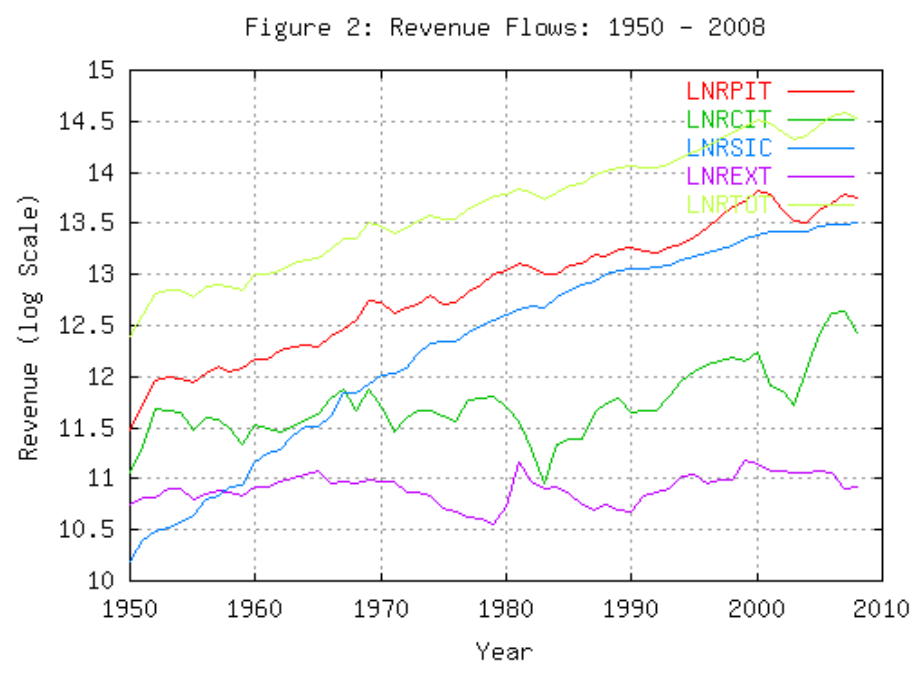

The data covers the period 1950-2008 and are obtained from the Office of Management of Budget (OMB) website. ${ }^{11}$ Figure 2 shows the pattern of personal, corporate, social insurance contributions, excise and total tax revenue, in real terms, over the above period. From the pattern of the data one can see that the personal, social insurance contributions and total tax revenue have trended upwards with fluctuations along the path, while corporate and the excise tax revenue do not show any apparent trend other than being very volatile.

\footnotetext{
${ }^{10}$ Barro (1979) has argued, governments appear not to change the rate schedule and tax code too frequently due to concern over the efficiency costs of the tax system. Thus even though observed variations in the growth rates of revenues may suffer from the noise due to legislative tinkering with the tax code, it can be shown that one may still obtain an estimate of the risk premiums implicit in the tax revenue flows. See also Groves and Kahn (1952).

11 The website is http://www.access.gpo.gov/usbudget/index.html. Table 2.1 of the historical data were used for the main tax receipts categories such as individual income tax receipts, corporate income tax receipt, social insurance contributions and retirement receipts, excise tax, and total receipts. The GDP and the deflator were obtained from table 10.1 of the same source.
} 
Table 3.1 provides some descriptive statistics on the real growth in various tax revenue, $g\left(R_{j t}\right)$ This table indicates that average rates of growth have been positive and quite large for the three largest tax revenue sources. The largest average growth is observed in social insurance contributions (SIC). The highest standard deviation is observed, not unexpectedly, in the case of the corporate income tax (CIT). Note that the volatility of CIT growth is significantly higher than most other public flows; the standard deviation for CIT is approximately 17 percent vs. 8 percent for the growth rate of the personal income tax revenue. The t-stats column for the sample average growth rate indicates that all the average growth rates are significant except for the corporate tax and the excise tax revenue. Observe that the year-on-year fluctuations in corporate tax revenue have been most volatile during the 1950-2008 period rendering its sample average value insignificant The table also shows that growth rate of GDP, denoted by $G(Y)$, over the same period has been very stable, which would imply a degree of flexibility of the tax system in absorbing aggregate risks.

Table 3.1: Descriptive Statistics on Revenue and GDP Growth Rates: 1950-2008

\begin{tabular}{|l|c|c|c|c|c|}
\hline \multicolumn{1}{|c|}{ Variable } & $\begin{array}{c}\text { Mean } \\
\text { Growth }\end{array}$ & $\begin{array}{c}\text { Standard } \\
\text { Deviation }\end{array}$ & $\begin{array}{c}\text { t-stats } \\
\text { For mean }\end{array}$ & $\begin{array}{c}\text { Minimum Growth } \\
\text { (year) }\end{array}$ & $\begin{array}{c}\text { Maximum } \\
\text { Growth }\end{array}$ \\
\hline GPIT & 0.0390 & 0.075 & 3.993 & $-0.166(06)$ & $0.264(51)$ \\
\hline GCIT & 0.0221 & 0.166 & 1.024 & $-0.340(01)$ & $0.393(84)$ \\
\hline GSIC & 0.0589 & 0.054 & 8.400 & $-0.009(02)$ & $0.216(51)$ \\
\hline GEXT & 0.0033 & 0.092 & 0.278 & $-0.184(82)$ & $0.425(81)$ \\
\hline GTOT & 0.0366 & 0.063 & 4.445 & $-0.091(02)$ & $0.217(51)$ \\
\hline G(Y) & 0.0332 & 0.022 & 11.65 & $-0.018(75)$ & $0.107(51)$ \\
\hline
\end{tabular}

Notes. The prefix-G in the first column denotes annualized growth rate; thus GPIT stands for the growth rate of PIT. Similarly for the other revenue categories, while G(Y) denotes the growth rate of GDP. The growth rates are computed as the difference in the natural logarithm from year to year. All data have been adjusted for inflation using the GDP deflator.

A tax revenue function can be represented as follows:

$R_{j t}=F\left(\tau_{t}\right) B_{j t}\left(F\left(\tau_{t}\right), Y_{j t}\right)$

where $R_{j t}$ is the real tax revenue received by the government from the $j$-th source, while $F\left(\tau_{t}\right)$ is the tax schedule, and $B_{j t}\left(F(\tau), Y_{j t}\right.$, denotes the tax base. The long run output is given by a function, $Y=Y(N, K, T)$, where the independent variables are population $(N)$, stock of capital $(K)$, technology $(T)$. Given $(3.1)$, it is hypothesized that the tax revenue is a stable exponential function of GDP, $R_{j t}=A Y_{t}^{\gamma_{j}} e^{\xi_{j t}}$, where $\xi_{j t}$ is a random error term with mean zero. It will be convenient to express the above in the log-linear form:

$\ln R_{j t}=\gamma_{0 j}+\gamma_{1 j} \ln Y_{t}+\xi_{j t}$

The $\gamma_{1 j}$-coefficient in the above regression is the long run output elasticity of tax revenue- $j$ [Sobel and Holcombe (1996), Williams et al. (1973)].

In order to examine if the revenue variables are co-integrated with GDP equation 3.2 is estimated and two tests are applied to examine if the two variables are co-integrated. The tests are the co-integrating regression Durbin Watson (CRDW) test and the augmented (where relevant) Dickey-Fuller test. ${ }^{12}$ The null hypothesis of no co-integration is rejected for personal and total income tax streams using both tests. The evidence based on both tests indicates that the personal income tax and the total revenue are co-integrated with GDP. While CIT, SIC, and ET are not co-integrated

\footnotetext{
12 The tests used were suggested by Engel and Granger (1987). The CRDW and the augmented Dickey-Fuller are considered more powerful tests.
} 
with GDP. ${ }^{13}$ Table 3.2 below presents the results: ${ }^{14}$

Table 3.2: Co-Integration Results

\begin{tabular}{|c|c|c|c|c|}
\hline $\begin{array}{c}\mathrm{C}_{\mathrm{o}} \text {-Integrating } \\
\text { Economic Variables }\end{array}$ & $\begin{array}{c}\text { Estimated } \\
\text { Co-Integrating } \\
\text { Coefficient using OLS }\end{array}$ & $\begin{array}{c}\text { R-Sq } \\
\text { From OLS } \\
\text { Estimation }\end{array}$ & $\begin{array}{c}\text { The CRDW } \\
\text { Test: } \\
\text { DW }=0\end{array}$ & $\begin{array}{c}\text { Augmented } \\
\text { DF Test: } \\
\gamma=0^{15}\end{array}$ \\
\hline${ }^{\text {PIT }}$ with GDP & 1.077 & 0.981 & 0.571 & -4.92 \\
\hline${ }^{\mathrm{CIT}}$ with GDP & 0.396 & 0.445 & 0.417 & -2.51 \\
\hline${ }^{\text {SIC }}$ with GDP & 1.739 & 0.971 & 0.079 & -1.24 \\
\hline EXT with GDP & 0.068 & 0.073 & 0.444 & -2.71 \\
\hline TOT with GDP & 1.042 & 0.991 & 0.866 & -5.01 \\
\hline
\end{tabular}

Note: The CRDW co-integration test is based on the Durbin Watson Statistics with Ho: DW $=0$. The critical value as reported by Sargan and Bhargava based on 10,000 simulations executed from 100 observations at the 5\%-level of significance is DW = 0.386. Care must be exercised since the current sample has only 59 observations. Therefore the $1 \%$ - level of significance instead of the standard $5 \%$ is chosen. At this level, the CRDW critical value is 0.511 . The critical value for the Dickey-Fuller cointegration test at the $10 \%$-level is 3.04

For the short run analysis an application of the theory of co-integration as developed by Granger (1981) and later expanded by Engel and Granger (1987) integrating the short run dynamics with long run equilibrium relationships is required. ${ }^{16}$ If the short run tax revenue and income variables are co-integrated then there exists an error correction mechanism such that the realised rate of growth of the actual revenue stream would depend on the growth rate of GDP and on the last period dis-equilibrium error obtainable from the long run relationship:

$g\left(R_{j t}\right)=a_{01}+a_{1 j} g\left(Y_{t}\right)+\rho_{1} \xi_{t-1}+a_{2 j} g\left(R_{j t-1}\right)+v_{j t}$.

In (3.3) $a_{1 j}$ measures the sensitivity of tax revenue with respect to output in the short run and will be used to compute the beta of the revenue flow once estimated. The coefficient $\rho_{1}$ lying in the $(-1,0)$-interval measures the speed with which the error, $\xi_{j t-1}=\ln R_{j t-1}-\left\lfloor\gamma_{0 j}+\gamma_{1 j} \ln Y_{t-1}\right\rfloor$, corrects the growth of tax revenue. If the revenue realised in the previous period exceeds the long run target then $\xi_{j t-1}>0$, and given that $\rho_{1}<0$, it will reduce this period's revenue growth. The closer is this parameter to zero the slower will be the speed of adjustment. In the absence of co-integration, estimation of (3.3) proceeds without the dis-equilibrium error term. The last term $g\left(R_{j t-1}\right)$ is used where necessary to make the error term white noise as required. The short run results are presented in Table 3.3, which demonstrates that there is a strong relationship between the growth behaviour of tax revenue and the evolution of the macro economy.

The largest short run tax elasticity is obtained for the corporate tax revenue. A one-percent drop in economic growth results in nearly four-percent drop in the growth rate of CIT revenue. Even though there may appear no significant relationship between the two variables in the long run, there is indeed a strong relationship at the level of short run fluctuations suggesting that CIT revenue carries significant systematic risk.

Corporate revenue apart, personal income tax and total tax revenues have income elasticities which are larger than the respective long run elasticities reported in Table 3.2. However, for both PIT and TOT, the growth

\footnotetext{
13 The absence of co-integration does not imply that a short run relationship does not exist between the two variables since differencing makes them stationary and the results cannot be spurious.

${ }^{14}$ Each of the variable examined, except EXT, has a unit root and hence is non-stationary. The results are available from the authors.

${ }^{15}$ The Augmented Dickey-Fuller test included a constant term but without a time trend in the auxiliary regression. The number of lags included in the augmented Dickey-Fuller test on the residuals are 1 for PIT, 0 for CIT, 0 for SIC, 0 for ET, and 0 for TOT.

${ }^{16}$ If in fact GDP and the revenue variables are found not to be co-integrated, it implies that either there is no long run relationship between the two variables or that there is a third variable that is missing from the specification.
} 
rate also depends strongly on last period's disequilibrium error (see column 4) as well as last period's growth rate. In fact, if the last period total revenue had increased beyond the sustainable long-run rate, say by 10 percent, the growth of revenue will fall (relative to the steady state rate) by about half this figure the following year. This implies that the government cannot merely increase the tax rate and expect an increase in the future growth rate of tax revenue if such a jump is not warranted by economic fundamentals. It is intuitive that tax revenue cannot grow beyond what is dictated by long run conditions. The speed of adjustment to the long run equilibrium is extremely rapid (i.e., two years for total revenue).

Table 3.3: Short run Income Sensitivity of Tax Revenue: 1950 - 2008

\begin{tabular}{|c|c|c|c|c|c|c|}
\hline Relation & $\begin{array}{l}\text { Constant } \\
\text { Term: } a_{0 j}\end{array}$ & $\begin{array}{l}\text { Senstivity factor } \\
\qquad a_{1 j}\end{array}$ & $\begin{array}{c}\text { Error Correction } \\
\text { Term }\end{array}$ & $\begin{array}{l}\text { g(Rit-1) } \\
\text { term: } a_{2 j}\end{array}$ & $\begin{array}{c}\text { Adjusted } \\
\text { R-Sq }\end{array}$ & D.W. \\
\hline GPIT with GGDP & $\begin{array}{l}-0.0292 \\
(0.012)\end{array}$ & $\begin{array}{l}1.616^{*} \\
(0.297)\end{array}$ & $\begin{array}{c}-0.387 * \\
(0.076)\end{array}$ & $\begin{array}{l}0.425 * \\
(0.077)\end{array}$ & 0.618 & 2.00 \\
\hline GCIT with GGDP & $\begin{array}{c}-0.1093 * \\
(0.034)\end{array}$ & $\begin{array}{l}3.956 * \\
(0.854) \\
\end{array}$ & NA & & 0.261 & 2.17 \\
\hline GSIC with GGDP & $\begin{array}{l}0.0224 \\
(0.012)\end{array}$ & $\begin{array}{l}1.098^{*} \\
(0.291)\end{array}$ & $\mathrm{NA}$ & & 0.186 & 1.83 \\
\hline GEXT with GGDP & $\begin{array}{l}-0.009 \\
(0.022)\end{array}$ & $\begin{array}{c}0.360 \\
(0.551)\end{array}$ & NA & & 0.000 & 1.91 \\
\hline GTOT with GGDP & $\begin{array}{l}-0.023 \\
(0.010)\end{array}$ & $\begin{array}{l}1.394^{*} \\
(0.248)\end{array}$ & $\begin{array}{r}-0.531 * \\
(0.097)\end{array}$ & $\begin{array}{l}0.394 * \\
(0.083)\end{array}$ & 0.635 & 2.44 \\
\hline
\end{tabular}

Notes: The growth rate of the variables is denoted by the prefix-G; thus GPIT denotes the growth in personal income tax. * indicates significance at the $1 \%$ level. NA denotes the non-applicability of the error term, as the variables in question happen not to be co-integrated with output. Standard errors are shown in parentheses below the estimated parameter.

\section{THE IMPLICIT RISK PREMIUM AND DISCOUNT RATES}

using

Combining the estimated values of the sensitivity terms in Table 3.3 and Table 2.1 above, the beta is computed

$$
b_{j}=\frac{\frac{\partial E\left(g\left(R_{j t}\right) \mid \Omega_{j}\right)}{\partial g\left(Y_{t}\right)}}{\frac{\partial E\left(r_{m t}-r_{f t} \mid \Omega_{m}\right)}{\partial g\left(Y_{t}\right)}}=\frac{a_{j}}{\lambda_{m}}
$$

for all the hypothetical assets that have exclusive claims on different tax categories analysed here. These are shown in the third column of Table 4.1 below. Following the security market equilibrium condition $E\left(\delta_{j}\right)=r_{f}+\beta_{j}\left(E\left(r_{m}\right)-r_{f}\right)$, the risk premia for different assets are calculated as the product of the market risk premium and the asset-specific beta's. Given the estimated market risk premium is 5.73, and column 3 figures, the asset specific risk premia are shown in column four of Table 4.1. The final column in Table 4.1 illustrates the discount rate applicable to assets, which is obtained by adding the average risk free rate of 2.18. From the table one can observe that the financial markets would demand a very large risk premium on the corporate tax revenue. The figure in question is even higher than that applicable on the market portfolio and hence the certainty equivalent is expected to be zero. However, the risk premium drops significantly if one uses the remaining revenue categories. The estimates highlighted above suggest that the discount rate applicable to total public revenue, which is typically the de facto collateral for all public debt, is 4.66 percent annually vis-à-vis the market rate of 7.9 percent. 
Table 4.1: Risk Premiums and Discount Rates: 1950 - 2008

\begin{tabular}{|l|c|c|c|c|c|}
\hline & & Sensitivity Factors & $\begin{array}{c}\text { Estimated } \\
\text { Beta }\left(\boldsymbol{b}_{\boldsymbol{j}}\right)\end{array}$ & Risk Premium & $\begin{array}{c}\text { Market Borrowing } \\
\text { Rate }\left(\boldsymbol{\delta}_{\boldsymbol{j}}\right)\end{array}$ \\
\hline GPIT & & 1.616 & 0.495 & 2.835 & 5.053 \\
\hline GCIT & & 3.956 & 1.211 & 6.941 & 9.158 \\
\hline GSIC & & 1.098 & 0.336 & 1.926 & 4.144 \\
\hline GEXT & & 0.360 & 0.110 & 0.632 & 2.849 \\
\hline GTOT & & 1.394 & 0.427 & 2.446 & 4.663 \\
\hline ERM & $\hat{\lambda}_{m}=$ & 3.266 & 1.00 & 5.73 & 7.90 \\
\hline
\end{tabular}

The government is able to borrow at lower rates than those reported in Table 4.1 for total revenue. Thus the risk premium is effectively zero for fluctuating tax revenue induced by aggregate shocks. The average short term risk free rate is estimated at 2.18 percent over this period and the estimated risk premium is 2.45 percent. Why is the risk premium of this size missing from government bonds? In the next section we offer some plausible reasons as to why it is absent.

\section{DISCUSSION AND CONCLUSION}

Why the risk premium attributable to fluctuating tax revenues does not form a part of the rate of return to private investors for holding government bonds has been addressed in the literature. One argument has been that the state's ability to engage in intergenerational risk sharing through a stochastic debt management policy renders risk premium insignificant (Gordon and Varian (1998)). The debt process typically pre-commits unborn generations in sharing aggregate risks with the current generation, which implies that the systematic risk facing a given generation becomes idiosyncratic when pooled with the independent lotteries of many generations to come. ${ }^{17}$ Another argument was brought forward by Pauly (1970). Pauly argued that the government has the ability to borrow at the risk free rate. He argued that "bonds are safe or certain because the government can always tax, either explicitly or implicitly by printing money, in order to pay interest on them" (1970, p196). The capital stock of a nation can serve as collateral. Thus the absence of a risk premium for fluctuating tax revenue occurs because the government is considered a trustworthy borrower provided the level of debt is not too high.

Long ago, Musgrave and Miller (1948) recognized the importance of the "built-in-flexibility" of the tax system as a stabilization device. In their view, the quantitative value of the flexibility depended on two elements. First, that taxes are a large proportion of income (i.e., average tax rates are relatively high) and secondly that they are income-sensitive. ${ }^{18}$ Groves and Kahn (1952) stated that fluctuations in tax revenue are a blessing and instability of taxes a virtue particularly at the federal level:

“.... the federal government whose special and strategic position in the economy makes deficits and surpluses from fluctuating revenue a blessing and hence instability of taxes (built-in flexibility) a virtue.....” (p. 88)

Thus the absence of the implicit risk premium for fluctuating tax revenue can also be interpreted as the value society places on the "built-in flexibility" of the tax system or instability of tax revenue. The government's ability to engage in intergenerational risk sharing through a stochastic debt management policy renders the risk premium on fluctuating tax revenue non-existent. The estimated implicit risk premium is 2.45 percent for the total revenue category which includes corporate tax revenue. The absence of this risk premium amounts to almost $\$ 1000$ per capita in interest savings if all debt is considered. The tax system removes some of the systematic risk from the private economy through the tax system and transfers it onto the budget constraint through its debt management policy spread across many generations.

In this paper we have developed a methodology to identify the existence of an implicit risk premium in tax revenue flows. We have also provided a number of reasons as to why the government can borrow at a lower rate than the risk adjusted discount rate found in this paper. Future research should attempt to identify the most important reason for the non appearance of this identified risk premium in government bonds.

\footnotetext{
${ }^{17}$ See also Ahsan and Tsigaris (1998).

${ }^{18}$ See Pearse (1962), Smyth (1966) for subsequent analysis.
} 
Possible applications of the methodology described in the paper can be used to estimate risk premiums of different types of human capital investments, small business valuations, social insurance benefits, and other publicly non-traded assets.

\section{AUTHOR INFORMATION}

Syed M. Ahsan is a Professor of Economics at Concordia University in Montreal, Quebec and is a member of the CESifo network. His principle areas of research are micro insurance, taxation and fiscal policy, and poverty, institutions and growth.

Panagiotis Tsigaris is an Associate Professor and Chairperson of Economics at Thompson Rivers University in Kamloops, British Columbia. His research interests span the areas of taxation issues and policy, environmental economics, decisions under risk, and the education of economics.

\section{REFERENCES}

1. Ahsan, S. M. and P. Tsigaris, (1998), "The Design of a Consumption Tax under Capital Risk", Journal of Economics /Zeitschrift fuer Nationaloekonomie, 68(1), 53-78.

2. $\quad$ Barro R., (1979), "On the Determination of Public Debt," Journal of Political Economy, 87, 940-971.

3. Bulow J.I. and L.H. Summers, (1984), "Taxation of Risky Assets," Journal of Political Economy, 92, 20-39.

4. Burmeister E., and K.D. Wall, (1986), "The Arbitrage Pricing Theory and Macroeconomic Factor Measures, The Financial Review, 21 (1), p 1-20.

5. Chen, N., R. Roll, and S.A. Ross, (1986), "Economic Forces and the Stock Market: Testing the APT and Alternative Asset Pricing Theories." Journal of Business, 59 (3), 383-403.

6. Dickey, D. A., and W. A. Fuller, (1979), "Distribution of the Estimators for Autoregressive Time Series with a Unit Root," Journal of the American Statistical Association, 74, 366, 427-431.

7. Engel, R. F., and C.W.J. Granger, (1987), "Co-integration and Error Correction: Representation, Estimation, and Testing," Econometrica, 55, 2, 251-276.

8. Gordon, R.H., and H.R. Varian, (1988), "Intergenerational Risk Sharing," Journal of Public Economics, 37, 185-202.

9. Groves, H. M., and C.H. Kahn, (1952), "The Stability of State and Local Tax Yields, " American Economic Review, 42, 2, 111-20.

10. Granger, C. (1981), "Some Properties of Time Series Data and their Use in Econometric Model Specification." Journal of Econometrics, 16, pp. 121-130.

11. Hayashi F., 2000, Econometrics, Princeton University Press.

12. Kaplow, L. (1994), "Taxation and Risk-Taking: A General Equilirium Perspective," National Tax Journal, 47, 789-798.

13. Lintner, J. (1965), "The Valuation of Risk Assets and the Selection of Risky Investments in Stock Portfolios and Capital Budgets," Review of Economics and Statistics, 13-37.

14. Maddison A. (1991), The Dynamic Forces in Capitalist Development: A Long Run Comparative View. Oxford, Oxford University Press.

15. Mehra, R. and E.C. Prescott, (1985), “The Equity Premium: A Puzzle”, Journal of Monetary Theory, 15, $145-61$.

16. Mossin, J., (1966), "Equilibrium in a Capital Asset Market," Econometrica, 768-83.

17. Musgrave, R.A., and M. Miller, (1948), "Built-In Flexibility," American Economic Review, 38, 122-128.

18. Myles, G.D. (1995), Public Economics, Cambridge University Press, Cambridge.

19. Pauly, M. (1970), "Risk and the Social Rate of Discount", American Economic Review, 60(1), 195-98.

20. Pearse, P.H., (1962), "Automatic Stabilization and the British Taxes on Income," Review of Economics and Statistics, 29(2), 124-139.

21. Ross, S.A. (1976), "The Arbitrage Pricing Theory of Capital Asset Pricing." Journal of Economic Theory, 4, 341-360

22. Sargan, J. D., and Bhargava, A., (1983), "Testing Residuals from Least Squares Regression for being generated by the Gaussian random Walk," Econometrica, 51, 153-174. 
23. Sharpe, W. F., (1964), "Capital Asset Prices: A Theory of Market Equilibrium under Conditions of Risk”, J of Finance, 19, 425-42.

24. Shiller, R., (1981), "Do Stock Prices Move Too Much to be Justified by Subsequent Changes in Dividends," American Economic Review, 421-36.

25. Smyth, D.J., (1966), "Built-in Flexibility of Taxation and Automatic Stabilization", Journal of Political Economy, 74(4), 396-400.

26. Sobel, R. S., and R. G. Holcombe (1996), "Measuring the Growth and Variability of tax Bases over the Business Cycle," National Tax Journal, 49 (4), 535-52.

27. Williams, W.V., R.M. Anderson, D.O. Froehie, and K.L. Lamb, (1973), "The Stability, Growth and Stabilizing Influence of State Taxes," National Tax Journal, 26, 2, $267-74$. 